\title{
Populasi Telur Nyamuk Aedes sp. Pada Ovitrap yang Diberi Fermentasi Gula Sebagai Atraktan Alami di Lingkungan Kampus FMIPA Universitas Lampung
}

\author{
SEKAR PRATIWI*, EMANTIS ROSA, PRIYAMBODO, TUGIYONO \\ Jurusan Biologi FMIPA Universitas Lampung, Bandar Lampung \\ Diterima: 1 Maret 2020 - Disetujui: 28 Agustus 2020 \\ (C) 2020 Jurusan Biologi FMIPA Universitas Cenderawasih
}

\begin{abstract}
Diseases transmitted by mosquito especially Aedes sp. there's still happens in many areas of both city and village in Indonesia, until reducing Aedes sp. requires controlled effort. Attractant is a compound that can effect the behavior of mosquito even to decrease the population of mosquito directly. Sugar fermentation can be a natural attractant, this solution can produce carbon dioxide compound that can be a attract for mosquito, until mosquitoes are attracted to ovitrap. The purposes of this research was to determined the sugar fermentation to total of Aedes sp. eggs at ovitrap. The research design used is a Complete Random Design (CRD) with 5 repeated. Analysis of data using Analysis of Variance (ANOVA) and if there are the significant differences of treatment then test continued with BNT test signification levels a $=5 \%$. The result is indicate that fermentation formula P1 (50 gr brown sugar+ $1 \mathrm{~g}$ yeast) found up to 15 mosquitos eggs at ovitrap with a percentage of $50 \%$ more than any other formula, ANOVA test indicate that the value of $p<0,05$ that's mean there is none significant differences between the treatment.
\end{abstract}

Key words: Aedes sp.; attractant; sugar fermentation

\section{PENDAHULUAN}

Di dunia diperkirakan terdapat lebih dari 2.500 spesies nyamuk, yang dibagi ke dalam 2 subfamili yaitu Culicinae yang memiliki 109 genus dan subfamili Anophelinae yang memiliki 3 genus. Dari kedua subfamili tersebut yang termasuk ke dalam subfamili Culicinae antara lain Aedes sp., Culex sp., dan juga Mansonia sp., sedangkan subfamili Anophelinae contohnya Anopheles sp. (Harbach, 2008).

Di Indonesia terdapat sekitar 457 jenis nyamuk yang terdiri dari 18 genus, dan jenis yang

* Alamat korespondensi:

1) Jurusan Biologi FMIPA Universitas Lampung. Jl. Prof.Dr. Sumantri Brokonegoro No.1 Bandar Lampung, Lampung. 35144. E-mail: pratiwisekar@yahoo.com paling banyak ditemukan berasal dari genus Aedes, Anopheles, Culex dan Mansonia yang juga dapat menjadi vektor utama penyakit (Widiyanti et al., 2016).

Nyamuk membutuhkan makanan dan nutrisi untuk kelangsungan hidupnya. Untuk memenuhi kebutuhan nutrisi dan proses berkembangbiak nyamuk memerlukan darah manusia atau darah hewan, seperti hewan ternak dan burung. Nyamuk betina dapat menghisap darah lebih dari satu orang untuk mencukupi kebutuhan darah, nyamuk betina dapat mati jika tidak mendapatkan cukup darah karena menyebabkan nyamuk tersebut tidak mendapat nutrisi dan mneghambat proses bertelurnya sedangkan nyamuk jantan cenderung menghisap sari buah untuk mempertahankan hidupnya (Syahribulan et al., 2012; Widiyanti et al., 2016). 
Untuk beraktivitas nyamuk Aedes sp. membutuhkan 3 tempat untuk kelangsungan hidupnya yaitu tempat beristirahat seperti di bawah pohon, di dinding rumah atau pada bendabenda yang berwarna gelap.

Tempat untuk melakukan aktivitas makan atau menghisap darah, Aedes sp. hinggap pada tempat yang dekat dengan mangsanya seperti kandang hewan atau berada di sekitar manusia (Firmanta, 2008). Tempat perindukan untuk proses perkembangan telurnya, ada beberapa tempat yang biasanya dijadikan tempat perindukan oleh nyamuk, tempat perindukan di dalam rumah seperti rumah seperti bak mandi, drum air, ember, dan vas bunga (Pohan et al., 2016). Dan tempat perindukan di luar rumah seperti kaleng-kaleng bekas, wadah minuman burung, genangan air, bambu dan lubang pada batu (Agustina \& Kartini, 2017).

Banyaknya tempat perindukan, menyebabkan populasi nyamuk meningkat. Berbagai upaya pengendalian telah dilakukan baik secara kimia maupun secara alami. Upaya pengendalian dengan menggunakan senyawa kimia telah dilakukan, tetapi penggunaan senyawa seperti larvasida atau insektisida yang terlalu sering dengan penggunaannya yang kurang tepat dapat menyebabkan nyamuk menjadi resisten terhadap zat atau senyawa tersebut (Hasanah et al., 2017).

Upaya pengendalian lain yang dapat dilakukan adalah dengan cara alami yaitu dengan menambahkan beberapa senyawa penarik nyamuk atau atraktan pada tempat perindukan. Penggunaan atraktan dalam beberapa kasus dapat menurunkan jumlah vektor demam berdarah dengue (DBD) cukup baik (Dwinata et al., 2015).

Atraktan berguna untuk mempengaruhi perilaku, bahkan dapat menurunkan angka populasi nyamuk secara langsung dan juga tidak memberikan efek atau dampak lain bagi hewan maupun manusia dan juga tidak memiliki dampak yang berarti pada bahan makanan (Geier et al., 1999). Menurut Hasanah et al. (2017) komposisi 50 gram gula merah, 1 gram ragi roti dan $100 \mathrm{ml}$ air merupakan komposisi paling efektif sebagai atraktan karena mampu memerangkap 152 ekor nyamuk, tetapi komposisi tersebut belum tentu menunjukkan hasil yang sama ketika diuji pada tempat yang berbeda. Oleh karena itu penelitian ini dilakukan untuk mengetahui fermentasi gula terhadap jumlah telur Aedes sp. yang ditemukan pada ovitrap dalam berbagai formula di lingkungan FMIPA Univeristas Lampung.

\section{METODE PENELITIAN}

\section{Waktu dan Tempat}

Penelitian ini dilaksanakan pada bulan Oktober hingga November 2019, di lingkungan FMIPA, dan di Laboratorium Zoologi Jurusan Biologi FMIPA Universitas Lampung.

\section{Alat dan Bahan}

Alat yang digunakan pada penelitian ini adalah ovitrap yang terbuat dari botol plastik, dan kertas saring; kuas, nampan, neraca analitik, cawan, spatula, mikroskop, kertas label, higometer, handcounter, lup, gelas ukur, termometer, erlenmeyer, buret, pipet tetes dan beaker glass. Sedangkan bahan yang digunakan pada penelitian ini adalah fermentasi gula yang terbuat dari campuran air, gula merah, dan ragi tape, cat, indikator PP (phenolphthalein), $\mathrm{Na}_{2} \mathrm{CO}_{3}$,

Tabel 1. Populasi telur Aedes sp. pada berbagai formula fermentasi gula merah dan ragi tape.

\begin{tabular}{|c|c|c|c|}
\hline \multirow[t]{2}{*}{ No } & \multirow{2}{*}{$\begin{array}{l}\text { Fermentasi Gula } \\
\text { (Gula merah+ragi } \\
\text { tape) }\end{array}$} & \multicolumn{2}{|c|}{ Jumlah telur pada TPA } \\
\hline & & Butir & $(\%)$ \\
\hline 1 & P1 & 15 & 50,00 \\
\hline 2 & P2 & 4 & 13,33 \\
\hline 3 & P3 & 1 & 3,33 \\
\hline 4 & P4 & 7 & 23,33 \\
\hline 5 & Kontrol & 3 & 10,00 \\
\hline & Total & 30 & 100,00 \\
\hline & Rata-rata & 6 & 20,00 \\
\hline & $\mathrm{p}$ & & 0,302 \\
\hline
\end{tabular}

Ket.:

P1 : 50 g gula merah $+1 \mathrm{~g}$ ragi tape

P2 : 30 g gula merah +2 g ragi tape

P3 : larutan $10 \mathrm{~g}$ gula merah

$\mathrm{P} 4 \quad$ : larutan 3 g ragi tape

Kontrol: air 
aquades dan telur Aedes sp. yang tertangkap.

\section{Cara Kerja}

Cara kerja dibagi kedalam 4 tahap yaitu pembuatan ovitrap, pembuatan atraktan, peletakkan ovitrap dan pengamatan sampel. Untuk data tambahan dilakukan juga pengukuran faktor kimia berupa kadar $\mathrm{CO}_{2}$ dan pengukuran faktor fisis lingkungan meliputi suhu dan kelembaban lingkungan.

\section{Analisis Data}

Metode penelitian ini menggunakan Rancangan Acak Lengkap (RAL) dengan 5× ulangan, data yang telah diperoleh dianalisis menggunakan uji Analysis of Variance (ANOVA), bila terdapat perbedaan yang signifikan antar perlakuan maka uji dilanjutkan dengan uji Beda Nyata Terkecil (BNT) pada taraf signifikasi $a=$ $5 \%$.

\section{HASIL DAN PEMBAHASAN}

\section{Jumlah Telur Aedes sp. yang Terdapat pada Ovitrap}

Jumlah telur Aedes sp. pada P1 formula (50 g gula merah $+1 \mathrm{~g}$ ragi tape) lebih banyak di bandingkan dengan formula yang lain yaitu sebanyak 15 butir dengan presentase sebesar $50 \%$, hal tersebut disebabkan karena P1 memiliki kadar $\mathrm{CO}_{2}$ yang tinggi yaitu sebesar 53,1 ml. Menurut Enny (2013) formula $100 \mathrm{~g}$ gula merah $+1 \mathrm{~g}$ ragi dapat memerangkap 80 ekor nyamuk, semakin banyak gula yang digunakan maka proses fermentasi dapat berjalan dengan baik sehingga kadar $\mathrm{CO}_{2}$ yang dihasilkan akan tinggi. Sedangkan menurut Hasanah et al. (2017) formula $50 \mathrm{~g}$ gula merah $+1 \mathrm{~g}$ ragi roti efektif untuk memerangkap telur dibuktikan dengan ditemukannya 152 nyamuk Aedes sp.

Jumlah telur Aedes sp. pada formula P4 (larutan $3 \mathrm{~g}$ ragi tape) sebanyak 7 butir telur dengan presentase $23,3 \%$, hal tersebut disebabkan karena kadar $\mathrm{CO}_{2} \mathrm{P} 4$ yang tinggi yaitu sebesar 42,8 $\mathrm{ml}$. Menurut Jerry et al. (2017) adanya reaksi antara air dengan ragi dapat menghasilkan $\mathrm{CO}_{2}$, pada penelitian Jerry dkk. larutan $5 \mathrm{~g}$ ragi dapat menghsilkan kadar $\mathrm{CO}_{2}$ sebanyak $23 \mathrm{ml}$ dan dapat mempengaruhi jumlah telur yang ditemukan yaitu sebanyak 842 ekor nyamuk dan 15,9\% diantaranya adalah jenis Aedes sp. sedangkan menurut Wahidah et al. (2016) atraktan ragi tape dapat memerangkap rata-rata 4 telur per ovitrap yang terpasang di luar ruangan.

Jumlah telur yang ditemukan pada ovitrap dengan formula P2 (30 g gula merah $+2 \mathrm{~g}$ ragi tape) ditemukan sebanyak 4 telur Aedes sp. dengan presentase sebesar 13,33\%, hal tersebut dapat terjadi karena P2 memiliki kadar $\mathrm{CO}_{2}$ sebesar $10 \mathrm{ml}$. Menurut Enny (2013) semakin sedikit gula yang digunakan akan menyebabkan proses fermentasi berjalan kurang baik yang dibuktikan dengan sedikitnya jumlah nyamuk yang tertangkap.

Pada kontrol (air) ditemukan sebanyak 3 telur Aedes sp. dengan persentase sebesar $10 \%$ dan memiliki kadar $\mathrm{CO}_{2}$ sebesar 5,8 $\mathrm{ml}$. Wijayanti \& Widyanto (2015) menyatakan bahwa semakin tidak pekat suatu larutan yang digunakan sebagai atraktan maka diduga larutan tersebut memiliki kadar $\mathrm{CO}_{2}$ yang rendah dan mempengaruhi jumlah nyamuk yang tertangkap.

Jumlah telur Aedes sp. pada P3 formula (10 g gula merah) hanya ditemukan 1 butir telur Aedes sp. dengan presentase sebesar 3,33\% dan memiliki kadar yang $\mathrm{CO}_{2}$ yang paling rendah yaitu sebesar $5,5 \mathrm{ml}$. Widya et al. (2015) penggunaan larutan gula sebagai atraktan tidak memberikan pengaruh pada nyamuk untuk hinggap dan meletakkan telurnya hal tersebut diduga karena kadar $\mathrm{CO}_{2}$ rendah pada larutan gula tersebut.

Uji ANOVA menunjukkan hasil nilai $p>0,05$ hal tersebut menunjukkan bahwa formula fermentasi tidak menunjukkan perbedaan yang signifikan terhadap jumlah telur Aedes sp. secara statistik.

\section{Pengukuran Faktor Kimia dan Fisik Lingkungan}

Pada formula P1 diketahui kadar $\mathrm{CO}_{2}$ sebesar 53,1 ml, menurut Enny (2013) ragi merupakan mikroorganisme yang untuk kelangsungan hidupnya membutuhkan nutrisi dan lingkungan hidup yang sesuai dan gula menjadi substrat yang 
disukai ragi. Adanya penambahan gula dapat memicu ragi untuk bekerja dan menghasilkan $\mathrm{CO}_{2}$. Enny (2013) juga menyatakan semakin banyak gula yang digunakan, maka proses fermentasi akan berjalan baik.

Pada perlakuan P4 diketahui kadar $\mathrm{CO}_{2}$ sebesar 42,8 ml, hal ini disebabkan karena adanya reaksi antara air dan ragi yang menghasilkan $\mathrm{CO}_{2}$. Kadar $\mathrm{CO}_{2}$ pada P2 sebesar $10 \mathrm{ml}$, menurut Enny (2013) semakin sedikit gula yang digunakan proses fermentasi berjalan kurang baik karena mikroorganisme pada ragi akan kekurangan nutrisi sehingga kadar $\mathrm{CO}_{2}$ menjadi rendah.

Untuk kadar $\mathrm{CO}_{2}$ pada kontrol sebesar 5,8 ml lebih rendah dibandingkan dengan formula lain, Wijayanti \& Widyanto (2015) menyatakan bahwa semakin tidak pekat suatu larutan yang digunakan sebagai atraktan maka diduga karena tidak adanya proses fermentasi sehingga kadar $\mathrm{CO}_{2}$ menjadi rendah. Kadar $\mathrm{CO}_{2}$ paling rendah yaitu pada perlakuan P3 sebesar 5,5 ml. Hal ini disebabkan karena tidak adanya penambahan ragi tape dan tidak terjadi fermentasi sehingga kadar $\mathrm{CO}_{2}$ menjadi rendah.

Diketahui bahwa suhu ketika penelitian berkisar antar $30-32{ }^{\circ} \mathrm{C}$ dengan rata-rata sebesar $30,8^{\circ} \mathrm{C}$. Kurniati et al. (2015) menyatakan bahwa suhu yang berkisar antara $24,3-28,1^{\circ} \mathrm{C}$ cocok bagi nyamuk untuk meletakkan telurnya, sedangkan menurut Astuti \& Nusa (2011) menjelaskan bahwa suhu antara $26-28{ }^{\circ} \mathrm{C}$ menjadi suhu yang ideal untuk perkembangan nyamuk sama halnya dengan Lala et al. (2018) bahwa suhu $28,1-29,56{ }^{\circ} \mathrm{C}$ dapat mempengaruhi kelangsungan hidup nyamuk.

Kondisi kelembaban lingkungan pada saat penelitian berkisar antara 50-53\% dengan rata-rata sebesar 51\%. Kurniati et al. (2015) menyatakan kelembaban yang efektif untuk nyamuk meletakkan telur dan juga untuk perkembangannya yaitu berkisar antara 60-89\% . Sedangkan Astuti \& Nusa (2011) menyatakan bahwa kelembaban yang cukup agar nyamuk dapat hinggap dan bertelur yaitu berkisar antara 60-64\%.

Pada penelitian ini kelembaban lingkungan kurang mendukung untuk nyamuk meletakkan telurnya, rendahnya kelembaban ini juga merupakan dampak lain dari tingginya suhu di tempat dilakukannya penelitian sehingga jumlah telur Aedes sp. yang ditemukan hanya sedikit.

\section{KESIMPULAN}

Berdasarkan hasil penelitian dapat disimpulkan bahwa fermentasi gula sebagai atraktan berpengaruh pada jumlah telur Aedes sp. yang ditemukan pada ovitrap. Formula fermentasi P1 (50 g gula merah +1 g ragi tape) ditemukan sebanyak 15 butir telur Aedes sp. pada ovitrap dengan persentase sebesar 50\% lebih banyak dibandingkan dengan formula yang lain.

Perlu adanya penelitian lebih lanjut mengenai jumlah telur Aedes sp. pada ovitrap setelah pemberian atraktan fermentasi gula dengan komposisi yang berbeda, atau dengan jenis atraktan lain.

\section{DAFTAR PUSTAKA}

Agustina, E., dan Kartini. 2017. Kajian tempat perindukan nyamuk Aedes di Gampong Ulee Tuy Kecamatan Darul Imarah Aceh Besar. Prosiding Seminar Nasional Biotik 2017. ISBN: 978-602-60401-3-8.

Astuti, E.P., dan R. Nusa. 2011. Efektivitas alat perangkap (Trapping) nyamuk vektor demam berdarah dengue dengan fermentasi gula. Aspirator. 3(1): 41-48.

Dwinata, I., T. Baskoro, dan C. Indriani. 2015. Autocidal ovitrap atraktan rendaman jerami sebagai alternatif pengendalian vektor DBD di Kabupaten Gunungkidul. Jurnal MKMI. 11(2): 125-131.

Enny. 2013. Perangkap nyamuk ramah lingkungan yang menggunakan bahan ragi untuk pengembang biakan kestabilan suhu dengan heat detector yang menggunakan NTC (Negative To Temperature Coeffisien). Metana. 9(2): 55-63.

Firmanta, Y. 2008. Deteksi resistensi nyamuk Aedes aegypti yang berasal dari daerah endemis dan non endemis dengue di Kota Jambi berdasarkan aktivitas enzim esterase non spesifik terhadap insektisida golongan piretroid. [Skripsi]. Universitas Sanata Dharma. Yogyakarta.

Geier, M, OJ Bosch, and J. Boeckh. 1999. Ammonia as an attractant component of host odour for the yellow fever mosquito, Aedes aegypti. Chem Senses. 24(6): 647-653.

Harbach. 2008. “DBD, Naskah lengkap pelatihan bagi pelatih dokter spesialis anak dan dokter penyakit dalam 
Tatalaksana DBD. Fakultas Kedokteran Universitas Indonesia. Jakarta.

Hasanah, H.U., D.S. Sukamto, dan I. Novianti. 2017. Efektivitas atraktan alami terhadap Aedes aegypti pada perbedaan warna perangkap. Jurnal Biologi dan Pembelajaran Biologi. 2(2): 23-32.

Jerry, D.C.T., T. Mohammed, and A. Mohammed. 2017. Yeastgenerated $\mathrm{CO}_{2}$ : A convenient source of carbon dioxide for mosquito trapping using the bg-sentinel traps. Asian Pacific Journal of Tropical Biomedicine. 7(10): 896-900.

Kurniati, A., I. Chahaya., dan Nurmaini. 2015. Efektivitas fermentasi gula sebagai atraktan nyamuk. http://id.123dok.com. Diakses pada 25 November 2019.

Lala, D., Suprijandani, dan Nurhaidah. 2018. Fermentasi air kelapa muda sebagai atraktan nyamuk Aedes aegypti. Gema Kesehatan Lingkungan. 16(1): 50-59.

Pohan, N.R., N.A.P. Wati, dan M. Nurhadi. 2016. Gambaran kepadatan dan tempat potensial perkembangbiakkan jentik Aedes sp. di tempat-tempat umum wilayah kerja Puskesmas Umbulharjo I Kota Yogyakarta. Jurnal Forum Ilmiah KesMas Respati. 1(2): 109-120.

Syahribulan, F.M. Biu, dan M.S. Hassan. 2012. Waktu aktivitas menghisap darah nyamuk Aedes aegypti dan
Aedes albopictus di Desa Pa'Lanassang Kelurahan Barombong Makassar Sulawesi Selatan. Jurnal Ekologi Kesehatan. 11(4): 306-314.

Wahidah, A., Martini, dan R. Hestiningsih. 2016. Efektifitas jenis atraktan yang digunakan dalam ovitrap sebagai alternative pengendalian vektor DBD di Kelurahan Bulusan. Jurnal Kesehatan Masyarakat. 4(1): 106-115.

Widiyanti, P.M. Ni Luh, K. Artawan, dan Ni P.S.R. Dewi. 2016. Identifikasi larva nyamuk yang ditangkap di perindukan di Kabupaten Buleleng. Prosiding Seminar Nasional FMIPA (268-276).

Widya, I.G.A.N., Sudjari, dan H. Aurora. 2015. Uji perbandingan potensi penambahan ragi tape dan ragi roti pada larutan gula sebagai atraktan nyamuk Aedes sp. Majalah Kesehatan FKUB. 2(4): 181-185.

Wijayanti, D.N., dan A. Widyanto, 2015. Efektivitas fermentasi air tebu sebagai bahan atraktan nyamuk Aedes aegypti Menggunakan Perangkap Nyamuk di Laboratorium Entomologi Jurusan Kesehatan Lingkungan Purwokerto Tahun 2015. Jurnal Keslingmas 34(1): 224-297. 